\title{
ANALISIS PERBANDINGAN PERFORMANSI WAKTU RESPONS KUERI ANTARA MySQL PHP 7.2.27 DAN NoSQL MongoDB
}

\author{
Olivia Maria Inacio Tavares ${ }^{1}$, Sartje Mala Rangkoly ${ }^{1}$, Sarah Sarah Desi Bawan ${ }^{1}$, \\ Ema Utami ${ }^{1}$, Muhammad Syukri Mustafa ${ }^{2}$ \\ ${ }^{\text {I} M a g i s t e r ~ T e k n i k ~ I n f o r m a t i k a, ~ U n i v e r s i t a s ~ A M I K O M ~ Y o g y a k a r t a ~}$ \\ J1. Ring Road Utara. Sleman, Yogyakarta, Indonesia \\ ${ }^{2}$ STMIK Dipanegara Makassar, Sulawesi Selatan \\ olivia.1280@students.amikom.ac.id, sartje.1291@students.amikom.ac.id, \\ sarah.1276@students.amikom.ac.id, ema_udamikom.ac.id, syukri@dipanegara.ac.id
}

\begin{abstract}
Curretly now, every function of the governmental and private agencies are required to manage the system work properly, effectively and certainly efficient in terms of both time and system flexibility. Not a few have used the use of basic management data to help maximize the work system that is being run. This research will be carried out by examining the performance when answering queries between 2 commonly used management database systems, namely the My Structured Query Language (MySQL) relational database and Not-Only SQL (NoSQL) MongoDB non-relational database tested on the Aspiration and Information Service System of Oebufu Village (SELMA) with the number of data records $(50,100,500,1000,5000,10000,100000)$. The examiner is carried out on the Data Manipulation Language (DML) query, wich is insert, update, delete and select functions in adding, modifying, and displaying data in the database. Testing is also carried out on the agreement function, namely Counting (COUNT), Total in 1 table (SUM), Average (AVG)functions as well as the AND OR liaison operator as well as testing data import and export. The research aims to provide the results of a performance comparison analysis between MySQL and MongoDB NoSQL query respond database to find out which one is more good fo use. The results can be proven that the two databases have different speeds in response performance comparisons in each model test, where NoSQL MongoDB is proven to be superior in every transaction tested model, starting from DML queries and fuction aggregate testing, import-export of data tables and intermediate operator function, but weak in comparing select queries to display data with a runtime difference of 1.95 .
\end{abstract}

Keywords: Database, Query Respond Time, MySQL, NoSQL, MongoDB.

\begin{abstract}
Abstrak - Saat ini, setiap fungsi kerja instansi kepemerintahan maupun swasta dituntut untuk dapat mengelola sistem kerja secara tepat, efektif dan tentunya efisien baik dari segi waktu maupun flexibilitas sistem. Tidak sedikit yang telah menggunakan pemanfaatan manajemen basis data dalam membantu memaksimalkan sistem kerja yang tengah dijalankan. Penelitian ini akan dilakukan pengujian kinerja waktu respond query diantara 2 sistem manajemen basis data yang telah umum digunakan yaitu database relasional My Structured Query Language (MySQL) dan database nonrelasional Not-Only SQL (NoSQL) MongoDB yang diujikan pada Sistem Layanan Aspirasi dan Informasi Kelurahan Oebufu (SELMA) dengan banyak record data (50, 100, 500, 1000, 5000, 10000, 100000). Adapun pengujian dilakukan pada query Data Manipulation Language (DML) yaitu pada fungsi insert, update, delete dan select dalam menambah, mengubah, menghapus serta menampilkan data pada database. Pengujian juga dilakukan terhadap agregat fuction yaitu pada fungsi Counting (COUNT), Total dalam 1 tabel (SUM), Average (AVG) juga pada operator penghubung AND OR serta pengujian import dan export data. Penelitian bertujuan memberikan hasil analisis perbandingan kinerja waktu respond query diantara MySQL dan NoSQL MongoDB untuk mengetahui basis data mana yang lebih unggul untuk digunakan. Hasilnya dapat dibuktikan bahwa kedua database tersebut memiliki kecepatan waktu yang berbeda dalam perbandingan kinerja respon kueri pada setiap model pengujian, dimana NoSQL MongoDB terbukti lebih unggul, mulai dari pengujian query DML, pengujian agregat fuction, impor-export data serta fungsi operator penghubung, namun lemah dalam pemrosesan query select untuk menampilkan data dengan jumlah selisih waktu respon 1,95s.
\end{abstract}

Kata kunci: Basis Data, Query Respond Time, MySQL, NoSQL, MongoDB

\section{PENDAHULUAN}

Menyikapi era globalisasi yang kian hari semakin berkembang dengan pesat, mulai dari penggunaan internet oleh berbagai kalangan tentunya memicu peningkatan digitalisasi fungsi kerja pada berbagai instansi kepemerintahan hingga swasta. Segala bentuk digitalisasi fungsi kerja tersebut saat ini telah menjadi salah satu tuntutan untuk dipenuhi [1], hal ini tentunya didukung pula melalui penggunaan model Database Management System (DBMS) untuk mengelola setiap data secara efisien dan efektif. Dewasa ini telah hadir begitu banyak inovasi teknologi basis data yang kian berkembang serta dimanfaatkan dalam pengaksesan data diantaranya adalah database relational dan database non-relational. Adapun pada database relational digunakan konsep data relations dalam tiap 
tabel serta mewarisi beberapa keunggulan diantaranya keteraturan struktur, penggunaan yang relativ mudah serta memiliki tingkat presisi yang tinggi, hal ini dikarenakan berbagai macam operasi aljabar dan kalkulus dilakukan dalam model basis data ini saat proses manipulasi relasi antar tabel sehingga mengurangi faktor ambiguitas pada data [2]. Sedangkan untuk basis data non-relasional Not Only $S Q L$ (NoSQL) model penyimpanan data berdasar tabel sudah tidak digunakan lagi, namun database ini menerapkan berbagai metode baru diantaranya adalah key-value, document oriented, graph dan lain sebagainya [3]. Selain itu keunggulan pada basis data ini yaitu dapat menyimpan data terstruktur, semi terstruktur dan tidak terstuktur secara efektif [4]. Contoh implementasi dari basis data relasional yaitu My Structured Query Language (MySQL) dan untuk Not Only SQL (NoSQL) yaitu MongoDB yang menerapkan metode document-oriented.

Hal tersebut, kemudian menghadirkan beragam pertanyaan baru, antara kedua basis data terkait manakah yang lebih efektif dan memiliki respon cepat dalam pemrosesan transaksi data. Berdasarkan berbagai hal yang telah diketahui seiring waktu maka kebutuhan akan data dan informasi akan selalu mengalami peningkatan yang tentunya kemudian akan mempengaruhi kecepatan waktu dalam pemrosesan transaksi data pada kedua model basis data tersebut.

Berdasarkan berbagai macam aspek keunggulan diantara kedua model Database Management System DBMS, maka penulis tertarik untuk melakukan analisa pengujian terhadap database relationa (MySQL) dan non-relational (NoSQL) tersebut menjadi sebuah topik penelitian yang akan diuji melalui perbandingan kinerja waktu respond query masing-masing DBMS dalam berbagai macam model pengujian untuk menghasilkan perbandingan yang tepat serta akurat.

Tujuan dilakukannya penelitian ini untuk membandingkan performansi waktu respon diantara database relational (yang diwakilkan oleh MySQL 7.2.27) dan database non-relational NoSQL (yang diwakilkan oleh MongoDB). Untuk dapat mengetahui manakah yang lebih efisien dan efektif maka akan dilakukan pengujian dengan menerapkan beragam skenario diantaranya, Pengujian terhadap query: DML (Data Manipulation Language) yaitu pada fungsi insert, update, delete dan select. Selanjutnya pengujian juga dilakukan pada agregat fuction yaitu pada fungsi COUNT, SUM, AVG juga pada pengujian import dan export data serta pengujian terhadap operator penghubung fungsi $A N D$ dan $O R$, yang akan diujikan dalam berbagai intensitas record data yang berbeda.

Manfaat dari penelitian ini untuk mengetahui model manajemen basis data manakah yang paling efektif serta efisien untuk digunakan sehingga kedepannya dapat dijadikan sebagai acuan dalam penggunaan model basis data yang paling cocok dan tepat sesuai kebutuhan pengguna. Terdapat banyak penelitian terdahulu mengenai perbandingan performa serta pengukuran waktu respon kueri diantaranya: Studi perbandingan performansi antara MongoDB dan MySQL dalam lingkungan big data [5], Perbandingan performansi database MongoDB dan MySQL dalam aplikasi file multimedia berbasis web [6], Perbandingan kemampuan NoSQL dan SQL kasus ERP Retail [7]. Perbandingan penggunaan NoSQL MongoDB dan MySQL pada basis data forum komunikasi [8].

Berdasarkan setiap penelitian tersebut rata-rata menyimpulkan performa NoSQL lebih efektif dan efisien dibanding MySQL. Hal ini membuktikan masih terdapat perbedaan signifikan antara kedua basis data tersebut dalam pemrosesan transaksi data yang perlu untuk diuji lebih lanjut menggunakan studi kasus yang berbeda agar dapat diperoleh hasil yang lebih tepat dan akurat dengan menambahkan lebih banyak bentuk pengujian dimana sebelumnya pengujian hanya dilakukan untuk menguji beberapa query Data Manipulation Language (DML) saja namun pada penelitian ini akan diujikan secara menyeluruh berserta dengan fungsi lainnya dengan pengujian sebanyak 3 kali untuk tiap testing query dalam beragam intensitas record data $(50,100,500,1000,5000,10000$ hingga 100000) record data dan dicatat lama waktu respon kueri yang didapatkan lalu kemudian hasilnya akan disajikan dalam perbandingan tabel dan grafik.

\section{METODE PENELITIAN}

Pada hakikatnya diantara database relasional MySQL dengan database non-relasional NoSQL MongoDB memiliki banyak perbedaan. Untuk dapat mengetahui perbedaan implementasi pemrosesan data dari kedua database tersebut maka akan dilakukan pengujian. Dalam penelitian ini penulis melakukan perbandingan query respond time diantara basis data MySQL dan NoSQL MongoDB yang dimana penulis menggunakan beragam model pengujian dengan setiap hasil uji coba yang akan dicatat waktu perolehannya secara signifikan sehingga lebih memaksimalkan hasil yang diperoleh untuk perbandingan kedua database.

Dalam penelitian ini tedapat 6 tahapan yang dilakukan antara lain: analisis sistem, identifikasi kebutuhan perangkat keras (hardware) dan perangkat lunak (software), penentuan dataset, perancangan tahapan pengujian, Implementasi dan pengujian, serta analisis hasil pengujian yang tertera pada Gambar 1:

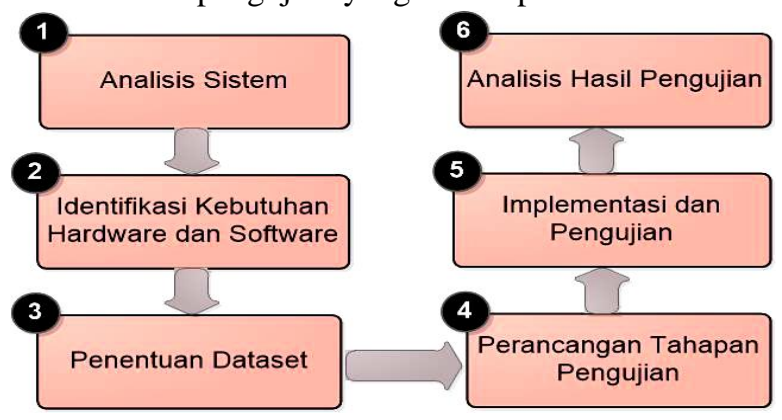

Gambar 1. Metode Penelitian 


\section{A. Analisis Sistem}

Dalam tahapan berikut dioperasikan analisa terhadap Batasan lingkup sistem secara general dari pengujian yang akan dilakukan. Untuk mengukur query response time ini akan melibatkan software, hardware serta dataset (sample data) yang akan digunakan dalam pengujian pada database relasional (MySQL) dan non-relasional (NoSQL).

\section{B. Identifikasi Kebutuhan Hardware dan Software}

Dalam tahap ini dijalankan identifikasi perangkat keras serta perangkat lunak yang dipergunakan dalam proses pengujian query response time kedua database.

Tabel 1. Spesifikasi Software yang Digunakan

\begin{tabular}{|l|l|l|}
\hline No & Software & Version \\
\hline 1. & Microsoft Windows & $10 / 64$ bit OS \\
\hline 2. & MySQL Xampp & PHP 7.2.27. \\
\hline 3. & MongoDB & Versi 4.2.7. \\
\hline 4. & MongoDB Compass & Versi 1.22 .1 \\
\hline
\end{tabular}

Tabel 2. Spesifikasi Hardware yang Digunakan

\begin{tabular}{|l|l|l|}
\hline No & Software & Version \\
\hline $\mathbf{1 .}$ & Memory & $8,00 \mathrm{~GB}$ RAM \\
\hline $\mathbf{2 .}$ & Processor & $\begin{array}{l}\text { Intel Core i7-7700HQ } \\
(2,80 \mathrm{GHz}) \text { DDR4 }\end{array}$ \\
\hline 3. & Graphic & Intel $^{\mathrm{R}}$ HD Graphics \\
\hline 4. & Harddisk & $1 \mathrm{~TB}$ \\
\hline
\end{tabular}

\section{Penentuan Dataset}

Untuk dataset pada studi kasus ini akan digunakan 2 jenis dataset berdasarkan data yang telah terinput pada Sistem Layanan Aspirasi dan Informasi Kelurahan Oebufu dengan tipe data JSON untuk diujikan pada MongoDB dan SQL untuk MySQL yang selanjutnya dilakukan pengaksesan sistem pada URL: http://oliviakeloebufu.com dengan percobaan record data mulai $(50,100,500,1000,5000,10000$ hingga 100000) dalam kumpulan data berupa text serta image.

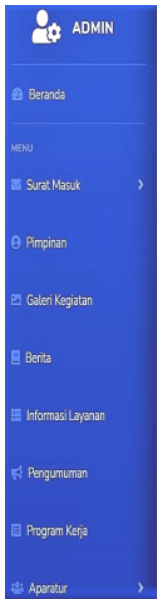

Beranda

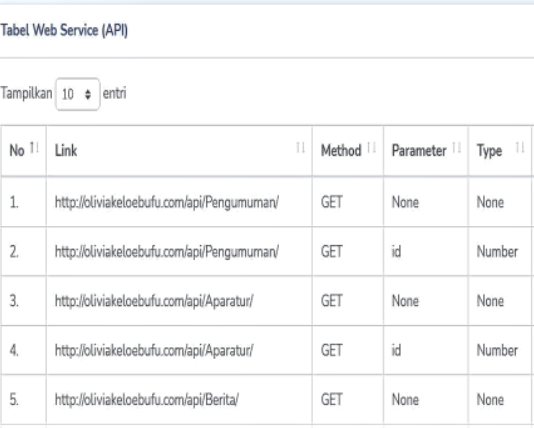

Gambar 2. Website (SELMA) Berisi Dataset Pengujian
Selanjutnya akan dianalisa kecepatan waktu respond kueri untuk setiap jumlah record data dengan menggunakan pengujian terhadap query insert, update, select dan delete, agregat fuction yaitu pada fungsi COUNT, SUM, AVG, juga pada pengujian import dan export data, operator penghubung pada fungsi AND dan OR setiap pengujian akan dilakukan testing sebanyak 3 kali untuk masing masing query.
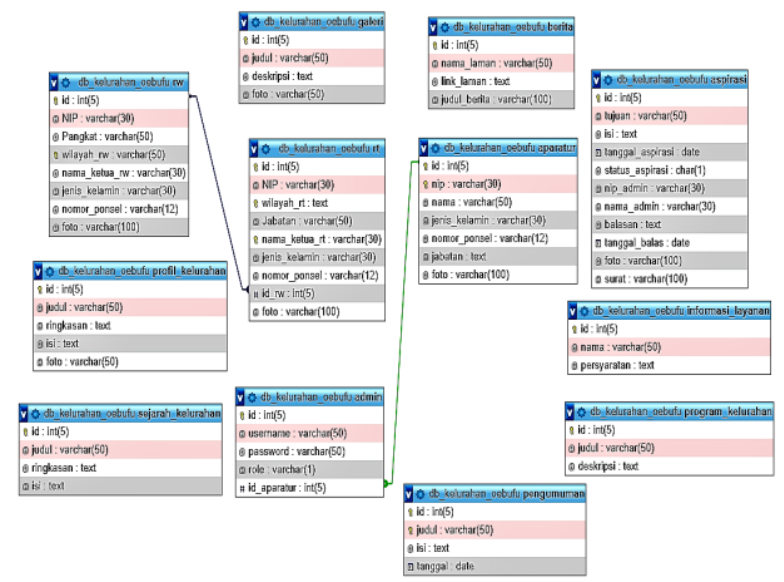

Gambar 3. Relasi Tabel Dataset pada Mysql

\section{Perancangan Tahapan Pengujian}

Pada tahapan ini akan dijabarkan langkahlangkah dilakukannya pengujian terhadap kedua basis data mulai dari melakukan pengujian terhadap query DML (fungsi insert, update, delete, dan select), kemudian pengujian terhadap fungsi agregat, pengujian import dan export data, dan yang terakhir yaitu pengujian operator penghubung (AND dan OR). Seperti tampak pada alur berikut ini.

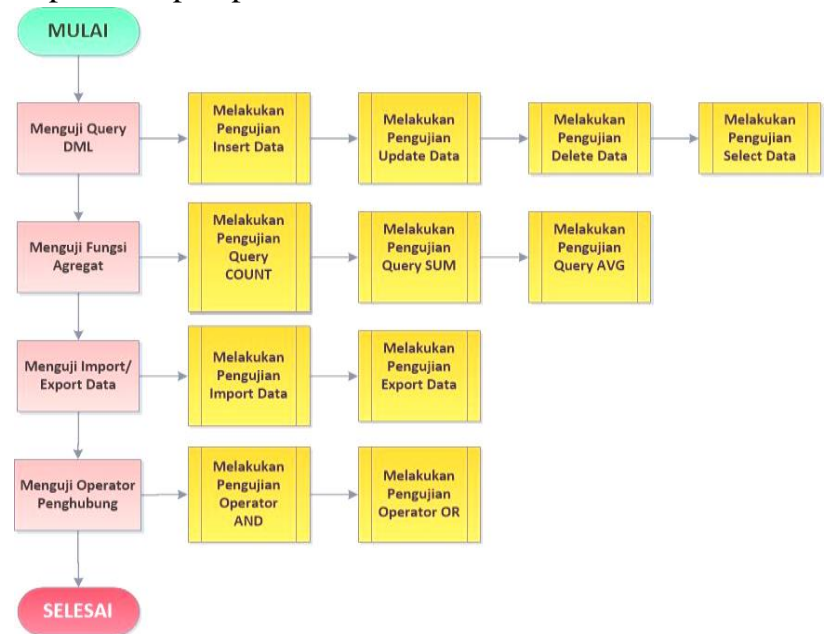

Gambar 4. Bagan Alur Pengujian

Dalam tahap ini telah dilakukan instalasi software (MySQL serta MongoDB Server dan Client) dengan hardware yang digunakan. Selanjutnya dilakukan konfigurasi pada kedua database server serta client agar saling terhubung untuk memulai pengujian. 
Model perancangan arsitektur sistem secara umum ditampilkan pada Gambar 5 berikut ini;

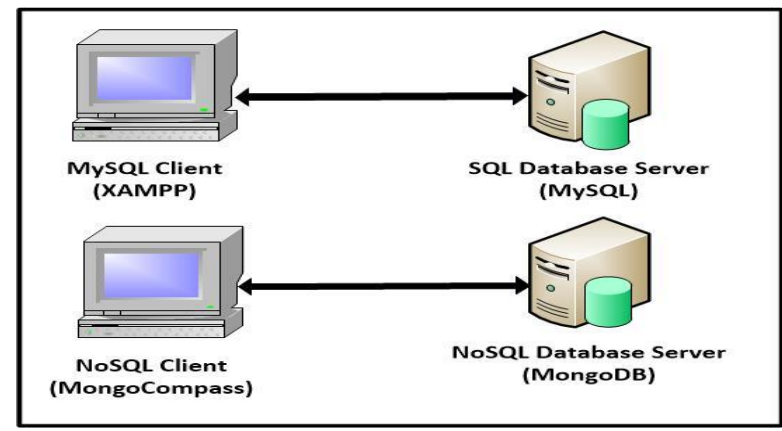

Gambar 5. Arsitektur Client Server Database

\section{E. Implementasi dan Pengujian}

Pada tahapan ini dimulai pengujian terhadap kedua model basis data dengan menampilkan implementasi langsung beserta dengan hasil pengujiannya dalam bentuk tabel dan grafik.

\section{Menguji Query DML}

Dalam pengujian ini akan dioperasikan sejumlah query DML (Data Manipulation Language) pada kedua model DBMS dengan menggunakan jumlah dataset yang sama agar setara dengan perbandingan yang diujikan adapun uji coba dilakukan sebanyak 3 kali dari 50 data dalam pengujian pertama lalu kemudian dilanjutkan pada percobaan berikutnya secara bertahap untuk dicatat runtime yang didapatkan.

a) Menguji Waktu Respon Insert Data

Dalam pengujian akan dilihat kemampuan penginputan data baru (insert data) dari basis data MySQL dan MongoDB. Untuk penjabaran model query ditampilkan berikut ini:

Mengujikan query insert untuk testing. Pada pengujian ini peneliti memilih menambah data pengumuman. Query yang dijalankan pada setiap database dijabarkan pada Gambar berikut:

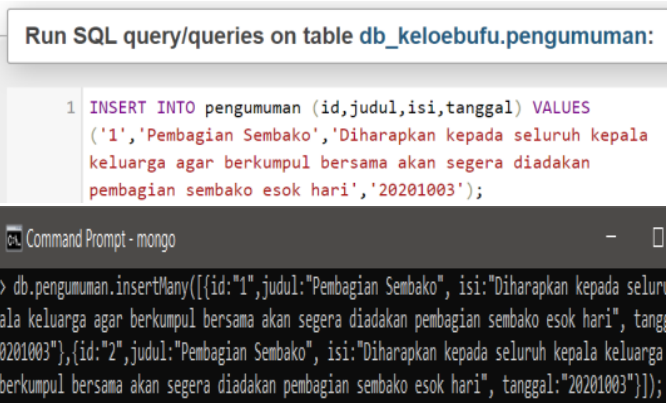

Gambar 6. Query Insert Mysql dan MongoDB

Pengujian berikut ini dilakukan pada tabel pengumuman sebagai tabel uji dengan menginputkan data yang sama sebanyak 50 hingga 100000 record data dalam kedua model basis data. b) Menguji Waktu Respon Update Data

Dalam pengujian ini akan ditampilkan kemampuan memperbaharui (update data) dari basis data MySQL dan MongoDB. Untuk penjabaran model query ditampilkan berikut ini: Mengujikan query update untuk testing. Pada pengujian ini peneliti memilih mengedit data pengumuman. Query yang dijalankan pada setiap database dijabarkan pada Gambar berikut:

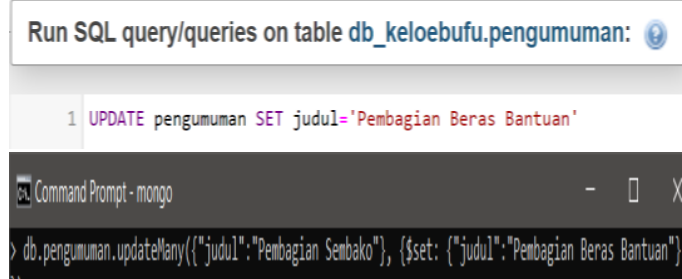

Gambar 7. Query Update Mysql dan MongoDB

Pengujian berikut ini dilakukan pada tabel pengumuman sebagai tabel uji dengan mengupdate data yang sama sebanyak 50 hingga 100000 record data dalam kedua model basis data.

c) Pengujian Waktu Respon Delete Data

Dalam pengujian ini akan dioperasikan pengujian untuk waktu respon menghapus data (delete data) dari basis data MySQL dan MongoDB. Untuk penjabaran model query ditampilkan berikut ini: Mengujikan query delete untuk testing. Pada pengujian ini peneliti memilih menghapus data pengumuman. Query yang dijalankan pada setiap database dijabarkan pada Gambar berikut:

Run SQL query/queries on table db_keloebufu.pengumuman:

1 DELETE FROM ‘pengumuman' WHERE id<51;

0i5. Select Command Prompt - mongo

$\mathrm{db}$. pengumuman. deleteMany $(\{\})$

Gambar 8. Query Delete Mysql dan MongoDB

Pengujian berikut ini dilakukan pada tabel pengumuman sebagai tabel uji dengan menghapus data yang sama sebanyak 50 hingga 100000 record data dalam kedua model basis data.

d) Menguji Waktu Respon Select Data

Dalam pengujian ini akan diujikan kemampuan menampilkan data (select data) dari basis data MySQL dan MongoDB. Untuk penjabaran model query ditampilkan berikut ini: 
Mengujikan query select untuk testing. Pada pengujian ini peneliti akan menampilkan data pengumuman. Query yang dijalankan pada setiap database dijabarkan pada Gambar berikut:

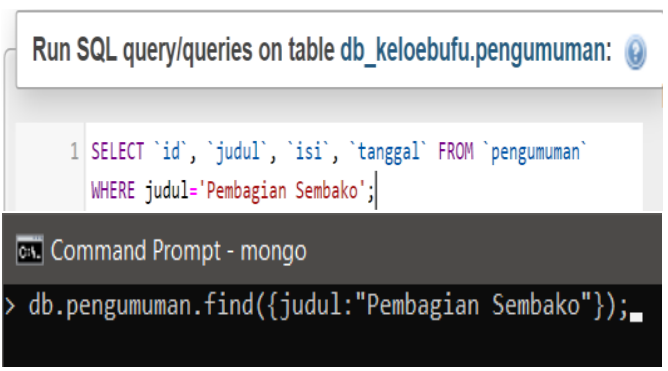

Gambar 9. Query Select Mysql dan MongoDB

Pengujian berikut ini dilakukan pada tabel pengumuman sebagai tabel uji dengan menampilkan data yang sama sebanyak 50 hingga 100000 record data dalam kedua model basis data.

\section{Menguji Fungsi Agregat}

Dalam pengujian ini akan dioperasikan sejumlah query fungsi agregat pada kedua model DBMS dengan menggunakan jumlah dataset yang sama agar setara dengan perbandingan yang diujikan adapun uji coba dilakukan sebanyak 3 kali dari 50 data dalam pengujian pertama lalu kemudian dilanjutkan pada percobaan berikutnya secara bertahap untuk dicatat runtime yang didapatkan.

a) Pengujian Waktu Respon Fungsi COUNT

Pada pengujian ini akan dibuktikan kemampuan menghitung jumlah record dalam database menggunakan fungsi COUNT dari basis data MySQL dan MongoDB. Untuk penjabaran model query beserta hasilnya ditampilkan berikut ini:

Mengujikan query COUNT untuk testing. Pada pengujian ini peneliti memilih menghitung jumlah data pengumuman. Query yang dijalankan pada setiap database dijabarkan pada Gambar berikut:

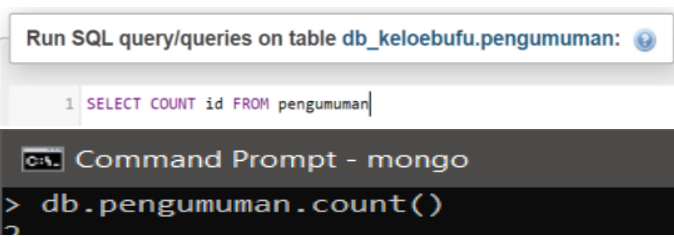

Gambar 10. Query COUNT Mysql dan MongoDB

Pengujian berikut ini dilakukan pada tabel pengumuman sebagai tabel uji dengan menghitung jumlah data mulai dari isian data sebanyak 50 hingga 100000 record pada kedua basis data. b) Pengujian Waktu Respon Fungsi SUM

Pada pengujian ini akan dibuktikan kemampuan untuk menjumlahkan kolom tertentu dalam database menggunakan fungsi sum dari basis data MySQL dan MongoDB. Untuk penjabaran model query ditampilkan berikut ini:

Mengujikan query SUM untuk testing. Pada pengujian peneliti memilih menjumlahkan seluruh isian data pengumuman. Query yang dijalankan pada setiap database dijabarkan pada Gambar berikut:

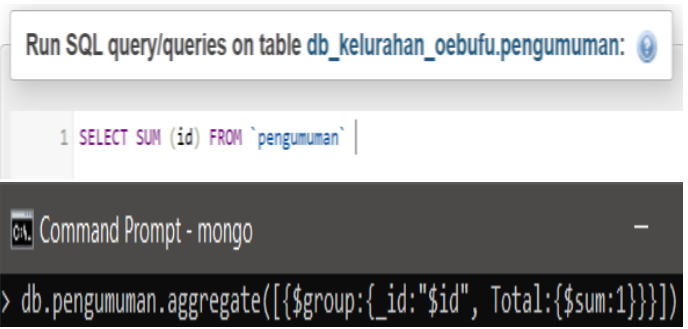

Gambar 11. Query COUNT Mysql dan MongoDB

Pengujian berikut ini dilakukan pada tabel pengumuman sebagai tabel uji dengan menjumlahkan setiap data mulai dari isian data sebanyak 50 hingga 100000 record pada kedua basis data.

c) Pengujian Waktu Respon Fungsi AVG

Pada pengujian ini akan dibuktikan kemampuan untuk menampilkan nilai rerata dari kolom tertentu dalam database dengan menggunakan fungsi AVG dari basis data MySQL dan MongoDB. Untuk penjabaran model query ditampilkan berikut ini:

Mengujikan query AVG untuk testing. Pada pengujian ini peneliti memilih menampilkan nilai rerata dari data tanggal pengumuman. Query yang dijalankan pada setiap database dijabarkan pada Gambar berikut:

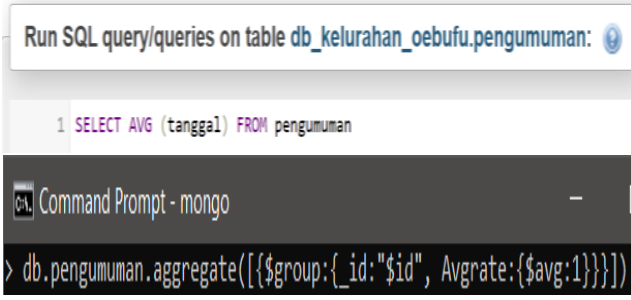

Gambar 12. Query AVG Mysql dan MongoDB

Pengujian berikut ini dilakukan pada tabel pengumuman sebagai tabel uji dengan menghitung rerata id setiap data mulai dari isian data sebanyak 50 hingga 100000 record pada kedua basis data. 


\section{Menguji Kemampuan Import/Ekspor Data}

Dalam pengujian ini akan diioperasikan sejumlah query fungsi agregat pada kedua model DBMS dengan menggunakan jumlah dataset yang sama agar setara dengan perbandingan yang diujikan adapun uji coba dilakukan sebanyak 3 kali dimulai dari 50 record data dalam uji coba pertama dan berlanjut pada percobaan berikutnya secara bertahap untuk dicatat runtime hasil uji coba yang didapatkan.

a) Pengujian Waktu Respon Impor Data

Pada pengujian ini akan dibuktikan kemampuan menautkan atau menginputkan isian data pada suatu database dari basis data MySQL dan MongoDB. Untuk penjabaran model query ditampilkan berikut ini:

Mengujikan impor data untuk testing. Pada pengujian ini peneliti memilih mengimpor data pengumuman pada database keloebufu secara berurutan per jumlah data dalam tabel mulai dari 50 data hingga 100000 dilihat performasi kecepatan waktu responnya pada database keloebufu. Pengujian yang dijalankan pada setiap database dijabarkan pada kedua gambar berikut:

\section{Mengimpor ke dalam tabel "pengumuman"}

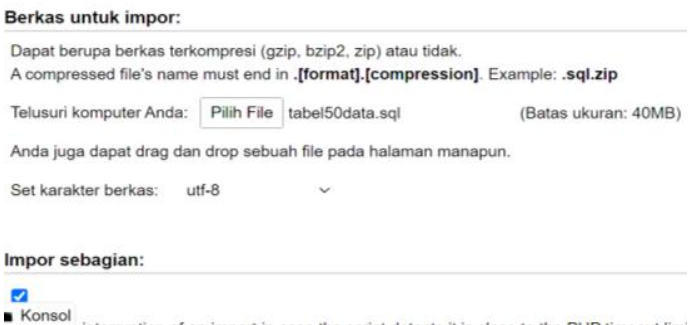

Gambar 13. Pengujian Impor data pada MySQL

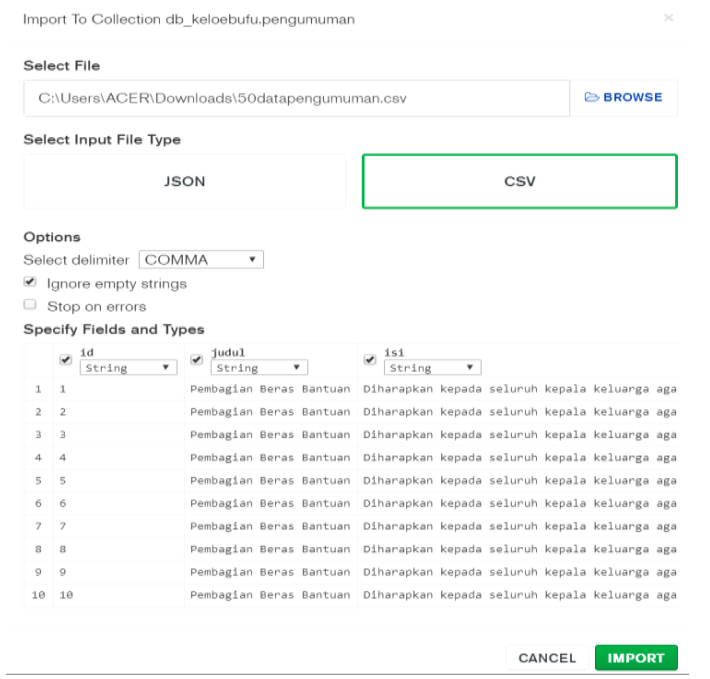

Gambar 14. Pengujian Impor Data pada MongoDB b) Pengujian Waktu Respon Ekspor Data

Pada pengujian ini akan dibuktikan kemampuan membuat salinan backup file database atau ekspor dari basis data MySQL dan MongoDB. Untuk penjabaran model query ditampilkan berikut ini: Mengujikan ekspor basis data untuk testing. Pada pengujian ini peneliti memilih mengekspor data pengumuman pada database keloebufu secara berurutan per jumlah data dalam tabel mulai dari 50 data hingga 100000 untuk dilihat performasi kecepatan waktu responnya. Pengujian yang dijalankan pada setiap database dijabarkan pada kedua gambar berikut:

\section{Mengekspor baris dari tabel "pengumuman"}

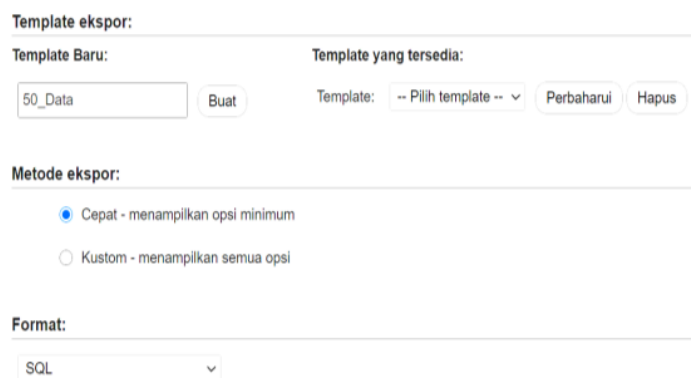

Gambar 15. Pengujian Ekspor Data MySQL

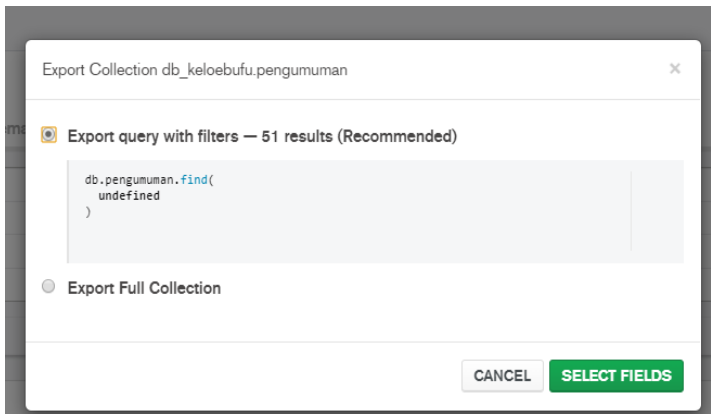

Gambar 16. Pengujian Ekspor Data MongoDB

\section{Menguji Operator Penghubung}

Dalam pengujian ini akan dioperasikan sejumlah query operator penghubung pada kedua model DBMS dengan menggunakan jumlah dataset yang sama agar setara dengan perbandingan yang diujikan adapun uji coba dilakukan sebanyak 3 kali dimulai dari 50 data untuk uji coba pertama dan berlanjut pada percobaan berikutnya secara bertahap untuk dicatat runtime hasil uji coba yang didapatkan.

a) Pengujian Waktu Respon Fungsi AND

Pada pengujian ini akan dibuktikan kemampuan operasi logika dalam membandingkan satu model data dengan data yang lainnya. Apabila satu keadaan bernilai TRUE lalu keadaan lainnya juga bernilai TRUE maka akan menghasilkan nilai TRUE namun jika satu keadaan saja yang bernilai FALSE maka hasilnya akan menjadi 
FALSE dalam database tersebut menggunakan pengujian AND dari basis data MySQL dan MongoDB. Untuk penjabaran model query ditampilkan berikut ini:

Mengujikan query $A N D$ untuk testing. Pada pengujian ini peneliti memilih membandingkan data pengumuman dimana akan digunakan query ini untuk menampilkan sejumlah data yang sesuai dengan etentuan yang ditetapkan pada query tersebut. Query yang dijalankan pada setiap database dijabarkan pada Gambar berikut:

\section{Run SQL querylqueries on table db_kelurahan_oebufu.pengumuman: 8 \\ SELECT *, id, isi FROM pengununan wHERE tanggal='20200212" AND isi='Diperingatkan agar seluruh pegawai menghadiri \\ Cii. Command Prompt - mongo \\ db.pengumuman.find(\{"id": "1", "judul": "Pembagian Beras Bantuan}

Gambar 16. Query AND Mysql dan MongoDB

b) Pengujian Fungsi OR

Pada pengujian ini akan dibuktikan kemampuan operasi logika untuk query OR berguna untuk operasi logika dalam database dalam bentuk perbandingan keadaan. Jika logika OR memiliki salah satu perbandingan yang bernilai TRUE maka hasilnya akan bernilai TRUE. Dari basis data MySQL dan MongoDB. Untuk penjabaran model query ditampilkan berikut ini:

Mengujikan query $O R$ untuk testing. Pada pengujian ini peneliti memilih membandingkan data pengumuman yang satu dengan yang lainnya. Query yang dijalankan pada setiap database dijabarkan pada gambar berikut:

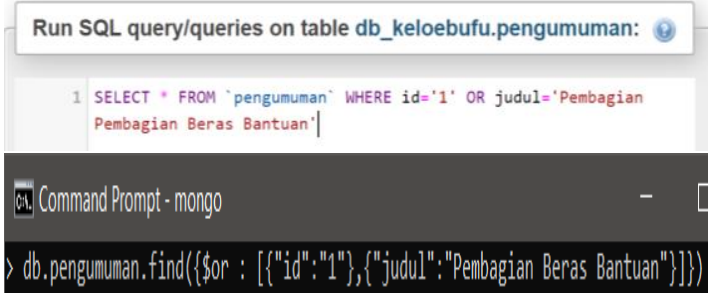

Gambar 17. Query OR Mysql dan MongoDB

Setiap data yang diujikan tersebut seluruhnya diimplementasikan pada tabel pengumuman dengan jumlah data yang sama dimulai dari 50 data hingga 100000 record data setiap daya yang diinputkan diuji secara berurutan mulai dari insert hingga pada model pengujian yang terakhir dan seterusnya pengujian dilakukan sebanyak 3 kali percobaan untuk memastikan waktu respon kueri yang dihasilkan kedua model basis data.

\section{HASIL DAN PEMBAHASAN}

Dalam setiap model pengujian yang dilakukan berikut akan dijabarkan hasil untuk masing -masing pengujian disajikan dalam bentuk tabel waktu respon kueri berserta dengan grafik agar lebih akurat serta mempermudah dalam pengambilan kesimpulan.

1. Hasil Pengujian Waktu Respon Insert Data

Berdasarkan data hasil waktu respon kueri yang yang terkumpul dalam 3 kali pengujian query berikut dijabarkan tabel dan grafik perbandingan runtime insert dari MySQL serta MongoDB:

Tabel 3. Hasil Pengujian Insert data

\begin{tabular}{|c|c|c|c|c|c|c|c|}
\hline \multicolumn{7}{|c|}{ HASIL PENGUJIAN INSERT DATA } \\
\hline Jumlah Data & 50 & 100 & 500 & 1000 & 5000 & 10000 & 100000 \\
\hline MySQL (sec) & 0,11 & 0,18 & 0,27 & 0,35 & 1,05 & 2,92 & 15,30 \\
\hline MongoDB (sec) & 0,04 & 0,06 & 0,15 & 0,22 & 0,37 & 1,27 & 8,00 \\
\hline
\end{tabular}

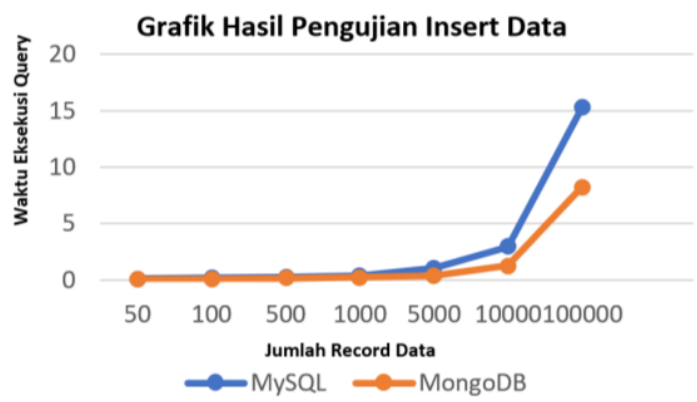

Gambar 18. Grafik Hasil Pengujian Update data

2. Hasil Pengujian Waktu Respon Update Data

Berdasarkan data hasil waktu respon kueri yang yang terkumpul dalam 3 kali pengujian query berikut dijabarkan tabel dan grafik perbandingan runtime update dari MySQL serta MongoDB:

Tabel 4. Hasil Pengujian Update data

\begin{tabular}{|c|c|c|c|c|c|c|c|}
\hline \multicolumn{7}{|c|}{ HASIL PENGUJIAN UPDATE DATA } \\
\hline Jumlah Data & 50 & 100 & 500 & 1000 & 5000 & 10000 & 100000 \\
\hline MySQL (sec) & 0,11 & 0,23 & 0,34 & 0,55 & 1,36 & 3,52 & 12,40 \\
\hline MongoDB $(\mathrm{sec})$ & 0,05 & 0,05 & 0,08 & 0,20 & 0,52 & 1,25 & 6,03 \\
\hline
\end{tabular}

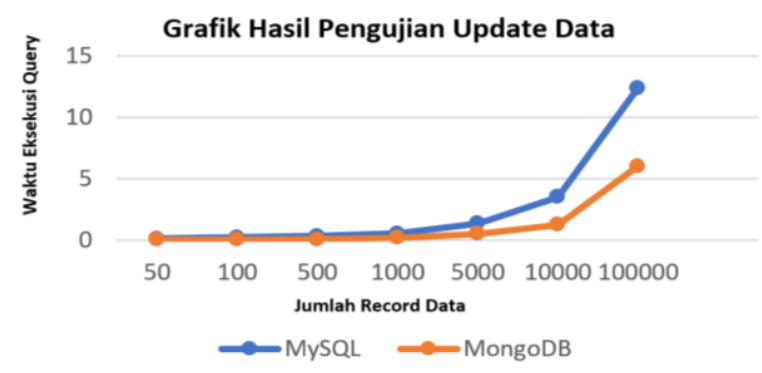

Gambar 19. Grafik Hasil Pengujian Update Data 
3. Hasil Pengujian Waktu Respon Delete Data

Berdasarkan data hasil waktu respon kueri yang yang terkumpul dalam 3 kali pengujian query berikut dijabarkan tabel dan grafik perbandingan runtime delete dari MySQL serta MongoDB:

Tabel 5. Hasil Pengujian Delete data

\begin{tabular}{|c|c|c|c|c|c|c|c|}
\hline \multicolumn{8}{|c|}{ HASIL PENGUJIAN DELETE DATA } \\
\hline Jumlah Data & 50 & 100 & 500 & 1000 & 5000 & 10000 & 100000 \\
\hline MySQL (sec) & 0,7 & 0,18 & 0,24 & 0,55 & 1,00 & 2,30 & 5,44 \\
\hline MongoDB (sec) & 0,01 & 0,03 & 0,06 & 0,20 & 0,53 & 1,33 & 2,00 \\
\hline
\end{tabular}

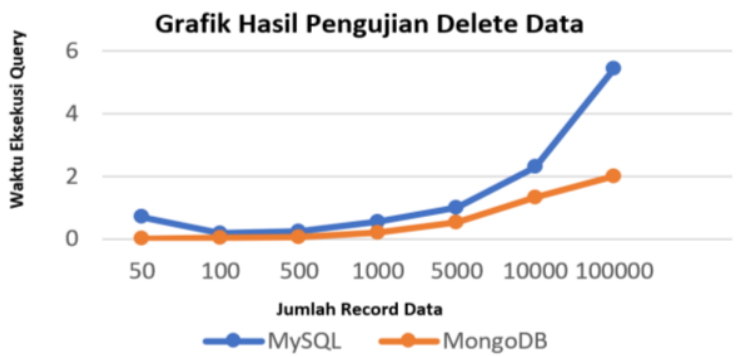

Gambar 20. Grafik Hasil Pengujian Delete data

4. Hasil Pengujian Waktu Respon Select Data

Berdasarkan data hasil waktu respon kueri yang yang terkumpul dalam 3 kali pengujian query berikut dijabarkan tabel dan grafik perbandingan runtime select dari MySQL serta MongoDB:

Tabel 6. Hasil Pengujian Select data

\begin{tabular}{|l|l|l|l|l|l|l|l|}
\hline \multicolumn{7}{|c|}{ HASIL PENGUJIAN SELECT DATA } \\
\hline Jumlah Data & 50 & 100 & 500 & 1000 & 5000 & 10000 & 100000 \\
\hline MySQL (sec) & 0,03 & 0,07 & 0,11 & 0,19 & 0,27 & 0,55 & 1,02 \\
\hline MongoDB (sec) & 0,06 & 0,08 & 0,18 & 0,28 & 0,34 & 1,20 & 2,05 \\
\hline
\end{tabular}

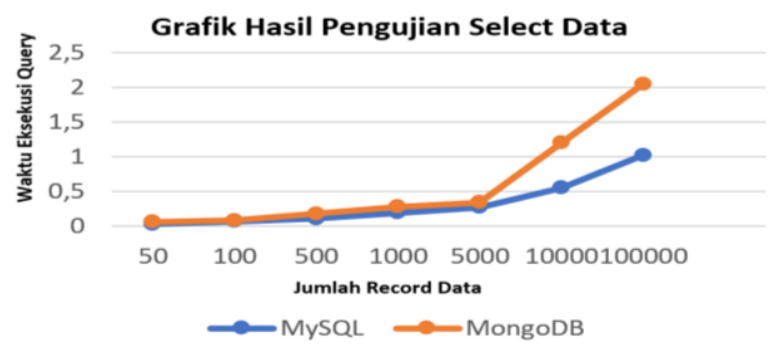

Gambar 21. Grafik Hasil Pengujian Select data

5. Hasil Pengujian Waktu Respon COUNT Data

Berdasarkan data hasil waktu respon kueri yang yang terkumpul dalam 3 kali pengujian query berikut dijabarkan tabel dan grafik perbandingan runtime COUNT dari MySQL serta MongoDB:
Tabel 7. Hasil Pengujian COUNT data

\begin{tabular}{|c|c|c|c|c|c|l|l|}
\hline \multicolumn{7}{|c|}{ HASIL PENGUJIAN COUNT } \\
\hline Jumlah Data & 50 & 100 & 500 & 1000 & 5000 & 10000 & 100000 \\
\hline MySQL (sec) & 0,11 & 0,30 & 0,42 & 0,54 & 1,02 & 1,36 & 3,77 \\
\hline MongoDB (sec) & 0,6 & 0,12 & 0,20 & 0,44 & 0,57 & 1,24 & 2,20 \\
\hline
\end{tabular}

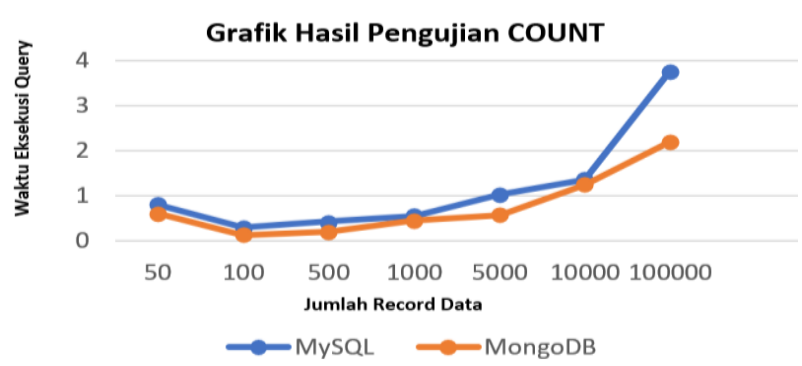

Gambar 22. Grafik Hasil Pengujian COUNT data

6. Hasil Pengujian Waktu Respon SUM Data

Berdasarkan data hasil waktu respon kueri yang yang terkumpul dalam 3 kali pengujian query berikut dijabarkan tabel dan grafik perbandingan runtime SUM dari MySQL serta MongoDB:

Tabel 8. Hasil Pengujian SUM data

\begin{tabular}{|c|c|c|c|c|c|c|l|}
\hline \multicolumn{7}{|c|}{ HASIL PENGUJAN SUM } \\
\hline Jumlah Data & 50 & 100 & 500 & 1000 & 5000 & 10000 & 100000 \\
\hline MySQL (sec) & 0,10 & 0,22 & 0,36 & 0,48 & 0,55 & 2,25 & 5,73 \\
\hline MongoDB & 0,6 & 0,17 & 0,27 & 0,33 & 0,47 & 1,07 & 3,30 \\
\hline
\end{tabular}

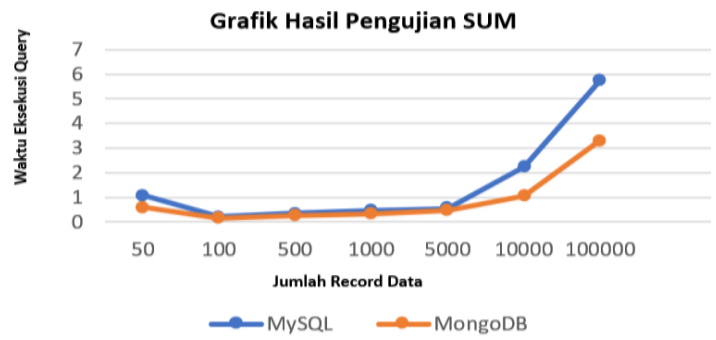

Gambar 23. Grafik Hasil Pengujian SUM data

7. Hasil Pengujian Waktu Respon AVG Data

Berdasarkan data hasil waktu respon kueri yang yang terkumpul dalam 3 kali pengujian query berikut dijabarkan tabel dan grafik perbandingan runtime AVG dari MySQL serta MongoDB:

Tabel 9. Hasil Pengujian AVG data

\begin{tabular}{|l|l|l|l|l|l|l|l|}
\hline \multicolumn{7}{|c|}{ HASIL PENGUJAN AVG } \\
\hline Jumlah Data & 50 & 100 & 500 & 1000 & 5000 & 10000 & 100000 \\
\hline MySQL (sec) & 0,16 & 0,27 & 0,34 & 0,44 & 1,02 & 1,36 & 3,40 \\
\hline MongoDB & 0,14 & 0,19 & 0,28 & 0,32 & 1,53 & 1,08 & 2,66 \\
\hline
\end{tabular}




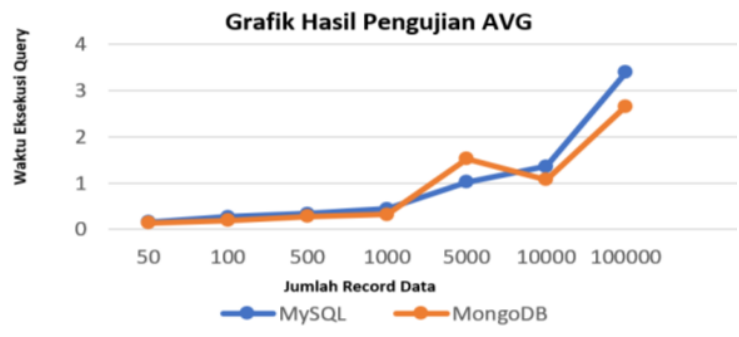

Gambar 24. Grafik Hasil Pengujian AVG data

8. Hasil Pengujian Waktu Respon Impor Data

Berdasarkan data hasil waktu respon kueri yang yang terkumpul dalam 3 kali pengujian query berikut dijabarkan tabel dan grafik perbandingan runtime Impor dari MySQL serta MongoDB:

Tabel 10. Hasil Pengujian Impor data

\begin{tabular}{|l|l|l|l|l|l|l|l|}
\hline \multicolumn{7}{|c|}{ HASIL PENGUJIAN IMPOR } \\
\hline Jumlah Data & 50 & 100 & 500 & 1000 & 5000 & 10000 & 100000 \\
\hline MySQL (sec) & 0,14 & 0,16 & 0,35 & 0,53 & 1,45 & 2,30 & 14,20 \\
\hline MongoDB & 0,5 & 0,11 & 0,26 & 0,42 & 1,23 & 1,53 & 11,00 \\
\hline
\end{tabular}

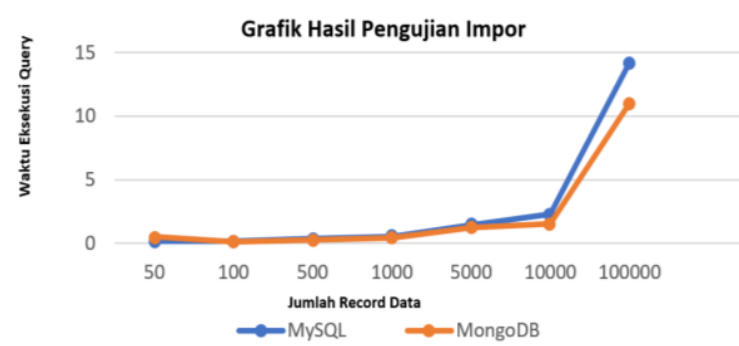

Gambar 25. Grafik Hasil Pengujian Impor data

9. Hasil Pengujian Waktu Respon Ekspor Data

Berdasarkan data hasil waktu respon kueri yang yang terkumpul dalam 3 kali pengujian query berikut dijabarkan tabel dan grafik perbandingan runtime Ekspor data dari MySQL serta MongoDB:

Tabel 11. Hasil Pengujian Impor data

\begin{tabular}{|l|l|l|l|l|l|l|l|}
\hline \multicolumn{7}{|c|}{ HASIL PENGUJIAN EKSPOR } \\
\hline Jumlah Data & 50 & 100 & 500 & 1000 & 5000 & 10000 & 100000 \\
\hline MySQL (sec) & 0,11 & 0,16 & 0,28 & 0,44 & 0,58 & 1,30 & 13,00 \\
\hline MongoDB & 0,5 & 0,12 & 0,17 & 0,37 & 0,45 & 0,58 & 11,08 \\
\hline
\end{tabular}

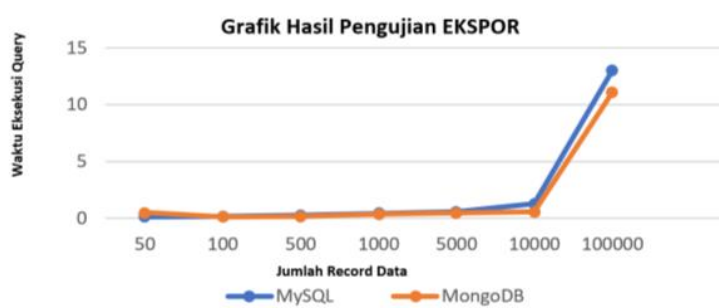

Gambar 26. Grafik Hasil Pengujian Impor data
10. Hasil Pengujian Waktu Respon Fungsi AND

Berdasarkan data hasil waktu respon kueri yang yang terkumpul dalam 3 kali pengujian query berikut dijabarkan tabel dan grafik perbandingan runtime Fungsi AND MySQL dan MongoDB:

Tabel 12. Hasil Pengujian Impor data

\begin{tabular}{|c|c|c|c|c|c|l|l|}
\hline \multicolumn{7}{|c|}{ HASIL PENGUJAN AND } \\
\hline Jumlah Data & 50 & 100 & 500 & 1000 & 5000 & 10000 & 100000 \\
\hline MySQL (sec) & 0,10 & 0,27 & 0,44 & 0,53 & 1,20 & 2,35 & 4,22 \\
\hline MongoDB & 0,7 & 0,15 & 0,25 & 0,32 & 0,50 & 1,00 & 2,32 \\
\hline
\end{tabular}

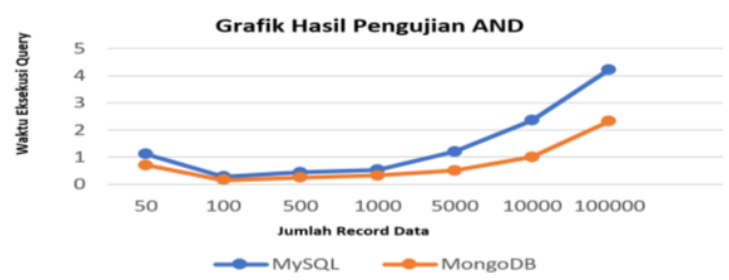

Gambar 27. Grafik Hasil Pengujian Fungsi AND

11. Hasil Pengujian Waktu Respon Fungsi OR

Berdasarkan data hasil waktu respon kueri yang yang terkumpul dalam 3 kali pengujian query berikut dijabarkan tabel dan grafik perbandingan runtime Fungsi OR MySQL dan MongoDB:

Tabel 13. Hasil Pengujian Impor data

\begin{tabular}{|l|l|l|l|l|l|l|l|}
\hline \multicolumn{7}{|c|}{ HASIL PENGUJIN OR } \\
\hline Jumlah Data & 50 & 100 & 500 & 1000 & 5000 & 10000 & 100000 \\
\hline MySQL (sec) & 0,7 & 0,14 & 0,27 & 0,38 & 0,55 & 1,40 & 5,06 \\
\hline MongoDB & 0,8 & 0,11 & 0,22 & 0,29 & 0,37 & 0,48 & 1,35 \\
\hline
\end{tabular}

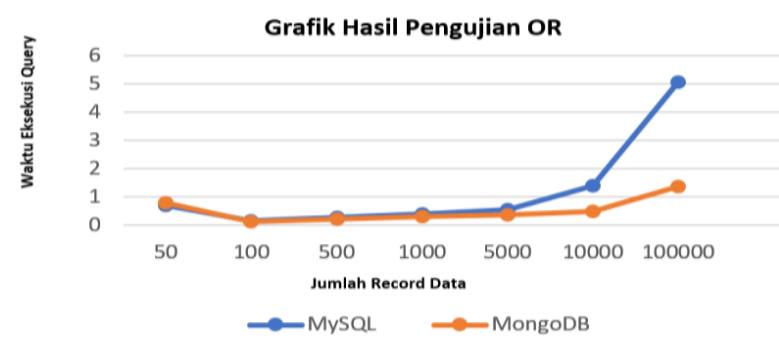

Gambar 28. Grafik Hasil Pengujian Fungsi OR

Berdasarkan seluruh hasil pengujian yang telah ditampilkan dalam menganalisis perbandingan kinerja query respond time pada MySQL 7.2.27 dan NoSQL MongoDB, peneliti telah memetakan setiap hasil pengujian sebagai berikut: 
Table 14. Runtime (/s) Hasil Pengujian

\begin{tabular}{|l|l|l|l|l|}
\hline \multirow{2}{*}{ No. } & \multirow{2}{*}{ Pengujian } & \multicolumn{3}{|c|}{ Total Keseluruhan Waktu Uji Coba } \\
\cline { 3 - 5 } & & \multicolumn{1}{|c|}{ MySQL } & \multicolumn{1}{|c|}{ MongoDB } & Selisih \\
\hline 1. & Insert & 20,18 & 10,11 & 10,07 \\
\hline 2. & Update & 18,51 & 8,18 & 10,33 \\
\hline 3. & Delete & 10,41 & 4,16 & 6,25 \\
\hline 4. & Select & 2,24 & 4,19 & 1,95 \\
\hline 5. & COUNT & 7,52 & 5,37 & 2,15 \\
\hline 6. & SUM & 9,69 & 6,21 & 3,48 \\
\hline 7. & AVG & 6,99 & 6,2 & 0,79 \\
\hline 8. & Impor & 19,13 & 15,05 & 4,08 \\
\hline 9. & Ekspor & 15,87 & 13,27 & 2,6 \\
\hline 10. & AND & 9,11 & 5,24 & 3,87 \\
\hline 11. & OR & 8,5 & 3,62 & 4,88 \\
\hline
\end{tabular}

Berdasarkan tabel perbandingan di atas maka dapat disimpulkan performansi query respond time dalam model pengujian DML dengan jumlah data ujian secara bertahap mulai dari 50 data hingga 100000 data terbukti MongoDB lebih unggul dalam proses eksekusi query insert, update dan delete sedangkan untuk query select (menampilkan data) proses respon dari database MySQL lebih cepat, selanjutnya untuk pengujian Agregat Function dengan jumlah data ujian secara bertahap mulai dari 50 data hingga 100000 data untuk semua query pengujian mulai dari fungsi COUNT, SUM dan AVG dapat disimpulkan waktu respon MongoDB lebih unggul jika dibandingkan dengan MySQL, selanjutnya pada pengujian import dan export data dengan isian jumlah data ujian secara bertahap mulai dari 50 data hingga 100000 data pada tabel menunjukkan MongoDB lebih unggul dibandingkan dengan MySQL serta yang terakhir yaitu pengujian Operator penghubung (AND) pada kedua database dapat dibuktikan MongoDB lebih unggul. Berdasarkan setiap hasil pengujian tersebut maka dapat disimpulkan bahwa rerata keseluruhan hasil pengujian menunjukkan performansi dari database NoSQL MongoDB jauh lebih efektif jika dibandingkan dengan MySQL, Adapun untuk fungsi menampilkan data MySQL memiliki keunggulan lebih cepat 1,95 detik dibanding MongoDB.

\section{KESIMPULAN}

Pada penelitian ini dapat disimpulkan bahwa database NoSQL MongoDB terbukti lebih unggul dalam setiap transaksi query yang diujikan dibandingkan dengan MySQL, namun lemah dalam pemrosesan transaksi query untuk menampilkan data dengan jumlah selisih runtime 1,95s. Penelitian ini membuktikan database NoSQL mampu memenuhi pemrosesan kebutuhan data yang besar dengan kecepatan waktu respond query yang optimal dan terbukti memiliki lebih banyak keunggulan dibanding database MySQL.

\section{DAFTAR PUSTAKA}

[1] O. M. I Tavares, "Analisis dan Perancangan Layanan Aspirasi dan Informasi Pada Kelurahan Oebufu," Jurnal Teknologi Terpadu (JTT), vol. 5, pp. 2477-0043, 2019.

[2] F Febryan, 2019, “Aplikasi Pengukur Tingkat Efektifitas Kerusakan Baja Jadi Menggunakan Metode Naïve Bayes," Doctoral dissertation, Universitas Buddhi Dharma.

[3] A. M. Bhugul, "Comparative Study of SQL \& NOSQL Databases,” Int. J. Sci. Res. Dev, vol. 3, no. 2, pp. 1496-1498, 2015.

[4] D. Damodaran, B. Salim, S. Vargese, S. Marium, "Performance Evaluation of MySQL and MongoDB Databases," International Journal on Cybernetics \& Informatics (IJCI), vol, 5 no. 2, pp. 10.5121, 2016.

[5] Junaidi. A. "Studi Perbandingan Performansi Antara MongoDB dan MySQL Dalam Lingkungan Big Data," In Annual Research Seminar (ARS), vol. 2, no. 1, pp. 460-465. 2017.

[6] Silalahi. M, "Perbandingan Performansi Database Mongodb Dan Mysql Dalam Aplikasi File Multimedia Berbasis Web," Computer Based Information System Journal, vol. 6 no. pp. 2337-8794, 2018.

[7] Bhaswara, F. Anugrah, S. Riyanarto S. Dwo, "Perbandingan Kemampuan Database NoSQL dan SQL dalam Kasus ERP Retail," Jurnal Teknik (ITS), vol 6 no. 2, pp. A511-A514, 2017.

[8] A. S. Daroini, Akhmad, "Perbandingan Penggunaan Nosql Mongodb Dan Mysql Pada Basis Data Forum Komunikasi,”. Jurnal Manajemen Informatika, vol 6 no.1, pp. 134142. 2017.

[9] E. Sutanta, "Basis Data dalam Tinjauan Konseptual", CV: Andi Offset, Yogyakarta. 2011.

[10] C. Thomas, B. Carolyn, "Database Systems A Practical Approach to Design, Implementation and Management" Fifth Edition: Pearson Education, Boston. 2010.

[11] Saputra A, "Manajemen Basis Data Mysql Pada Situs FTP Lapan Bandung," Berita Dirgantara, vol 13 no 4, pp. 155-162, 2012.

[12] Komputer W, "Panduan Belajar MySQL Database Server,” Mediakita, Jakarta. 2010.

[13] Priyanto R, "Belajar Sendiri: Menguasai MySQL 5, Elex Media Komputindo, Jakarta, 2013.

[14] Tambunan, D. D, 2016, "Perbandingan Analisis Aplikasi Database NoSQL Redis dan SQL 
MySQL," Doctoral dissertation, Universitas Widyatama.

[15] M. Milan, D. Dalibor, P. Ivana, "Example of Iot Platform Usage for Wireless Video Surveillance With Support of NoSQL And Cloud Systems," On Proceedings Of The $6^{\text {th }}$ International Conference Applied Internet And Information Technologies, pp. 9989-870-75-6, 2016.

[16] Y. Li \& S. Manoharan, A Performance Comparison of SQL and NoSQL Databases. In 2013 IEEE Pacific Rim Conference on Communications, Computers and Signal Processing (PACRIM), pp. 15 19, 2013.

[17] Győrödi. C, Győrödi. R, Pecherle. G, Olah A. A Comparative Study: MongoDB vs. MySQL, In $201513^{\text {th }}$ The International Conference on Engineering of Modern Electric Systems (EMES) (pp. 1-6), IEEE, 2015 l., vol. 3, no. 1, p. 73, 2017. 